\title{
Sea experimental detection of an array of hollow spheres
}

\author{
Rafael CARBÓ and Adriana C. MOLERO \\ Instituto de Acústica (C.S.I.C.), Serrano 144, 28006 Madrid, Spain \\ e-mail : iaccf31@fresno.csic.es
}

\begin{abstract}
SUMMARY
A study of the acoustic backscattering produced by an array of scattering spheres fixed to a fishing net is reported. The system enhances net detection and also allows net identification by using a method in which the echogram is arranged to resemble a commercial bar-code. A simplified theoretical model has been developed to study the interference due to echo formation. This model establishes the relations between system geometry (target dimensions, scatterer separation and net depth) and sonar performance (directivity, pulse length, pulse repetition rate, wavelength, and ship speed), getting a better system response. Experimental tests have been realized in a water tank in good agreement with bar code gillnet identification provided by the theoretical model. A sea survey in the Mediterranean sea has been carried out. It has been placed a gillnet with an array of plastic hollow spheres attached at the headline of the net. Several measurements were taken with a side scan sonar to detect the net and identify the associated bar code.
\end{abstract}

\section{INTRODUCTION}

Sometimes the marker buoys of gillnets disappear and it is necessary to detect the net resting on the sea bed with sonar techniques to avoid the "ghost fishing" problem whereby lost nets continue to kill fish unnecessarily. It is also important to identify pipes and other devices submerged under the sea. In this work it has been tried to increase the acoustic backscattering from a gillnet by attaching an array of scatterers. It has been simulated and experimented with different array geometries in a water tank and in a sea survey.

The goal of this work is not only to improve the detection of submerged devices, but also to identify them by means of a distinctive pattern in the echogram. This pattern resembles a bar code with its wide or narrow bars and gaps, see Fig.1. The bar code is controlled by a detailed arrangement and separation of the scatterers.

Narrow and wide echo zones associated with the former mentioned narrow and wide bars may be distinguished by means of simple equations that compute the length (SL) and target strength (TS) of each echo zone. TS and SL values are functions of the geometrical array parameters: (scatterer radius $a$, number of scatterers $N$ and scatterers separation $d x$ ); functions of the sonar performances: (beam width $\Phi$ and pulse length $\tau$ ), and functions of the net depth $z$. 


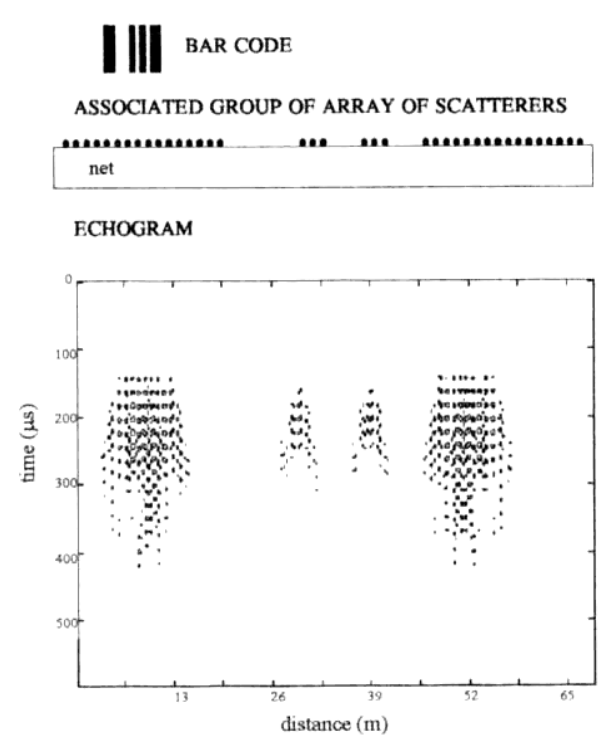

Fig. 1. Bar-code associated, scatterers arrays system attached to the headline of a net and simulated echogram produced by the system.

\section{LABORATORY EXPERIMENTAL RESULTS}

A $5 \mathrm{~m}$ section of a gillnet including floats and leads, has been placed at the bottom of a water tank ( $7.5 \mathrm{~m}$ long, $4.5 \mathrm{~m}$ wide, $4.5 \mathrm{~m}$ deep). The echogram is recorded by moving the echosounder transducer along the net area. The selected geometrical parameters from the theoretical simulation, defining the scatterers arrangement are the following: 50 scatterers in all (polyurethane spheres $4.4 \mathrm{~cm}$ diameter) split into two large arrays with 17 scatterers each and two short arrays with 8 scatterers each. The sonar transducer (Raytheon V-700) works at $200 \mathrm{kHz}$.

The target strength of the unmodified gillnet was evaluated and the result was - $43 \mathrm{~dB}$. With only the gillnet mesh being insonified the target strength decreased to $-52 \mathrm{~dB}$. The TS of a isolated sphere has shown to be $-39 \mathrm{~dB}$ in tank studies.

The Fig. $2 \mathrm{a}$ shows the resulting echogram. The areas where the target strength were enhanced by $10 \mathrm{~dB}$ form an easily visualized bar code. The TS of the headline is much lower than the array of scatterers one. It can be greatly appreciated at Fig. $2 \mathrm{a}$ the acoustic equivalence of a bar code of 4 sections : two wide bars and two narrow ones, separated by a wide gap between third and fourth bars, and narrow gaps between first and second, and second and third bars. On this way it can be identify the code attached to the lost gillnet.

To compute the backscattered echo strength we have developed a software and the same conditions referred above were introduced to simulate the experimental set up. As a result the theoretical echogram shown in Fig. $2 \mathrm{~b}$ has been obtained. Notice the good agreement between the 
theoretical and experimental echograms. The experimental echogram presents a curved aspect caused by the irregular buoyancy of different sections of the gillnet.
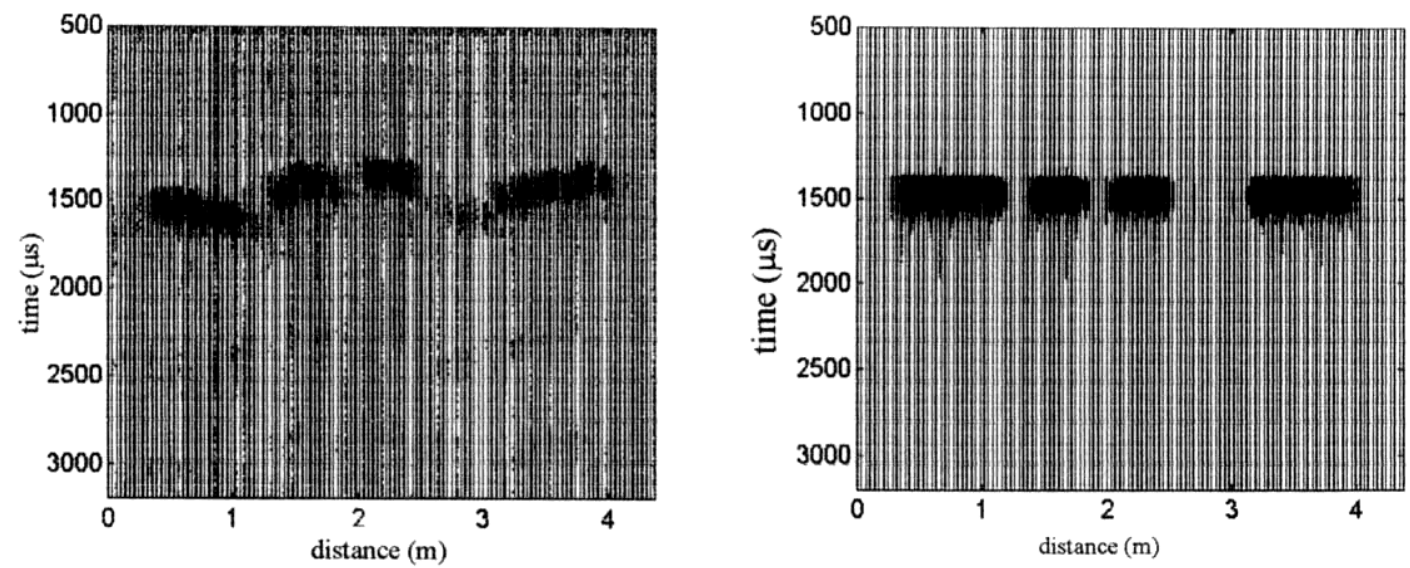

Fig. 2 Experimental (a) and theoretical (b) echogram of a scatterer array resembling a commercial bar-code.

\section{SEA SURVEY RESULTS}

The sea survey took place in the Mediterranean sea, at the south of Spain in a village called

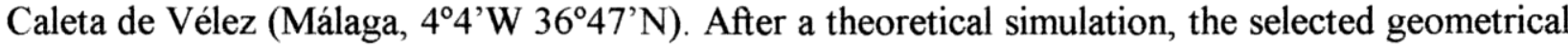
parameters defining the scatterers arrangement are the following: 26 scatterers in all (PVC spheres $9.6 \mathrm{~cm}$ diameter and a central hole of $1.5 \mathrm{~cm}$ diameter) split into two arrays with 18 scatterers one and with 8 scatterers the other. The scatterer separation is $1 \mathrm{~m}$ inside each array, the gap between arrays is $19 \mathrm{~m}$ long. The depth was around $20 \mathrm{~m}$, and seabottom was mud and gravel. It was used a side scan sonar to cover a wide area, working at $500 \mathrm{kHz}$.

From the signal acquired, and with the methodology mentioned before, an example of two of the echograms done are presented in Fig. 3 and Fig. 4. The echo from the net between 30 and $50 \mathrm{~ms}$ can be clearly seen. For a better understanding of the figures it is important to notice the direction of the ship during each transecto.

Fig. 3 goes from west to east, and fig. 4 from east to west. In that sense, the numbered transecto 14 was tested first in the long section of attached buoys (18 spheres), and next tested in the short section ( 7 spheres). At the further transecto (Fig. 4) was necessary to correct the effect of distance by a time-variation gain because the loss of signal amplitude.

The results demonstrate that the proposed method is suitable for depths similar to the ones used in these tests on bottom-set nets. Consequently, the objective of the work was partially achieved because the net was completely localized, and in some cases the acoustic code was distinguished, mostly when the net had a large number of spheres on it. 


\section{CONCLUSIONS}

It has been shown that a gillnet's detection and identification can be improved by attaching a scatterer array system to the headline. The objective of this work cannot be achieved by simply altering the dimensions, material or other characteristics of the gillnet. It is necessary to add external elements with target strength greater than that of the largest fish normally entangled to the net. A theoretical simulation has been developed. It has been demonstrated, theoretically and experimentally, the possibility of net identification by arranging the scatterers to form codes similar to commercial bar codes in an underwater tank, and the possibility of net location in the sea.

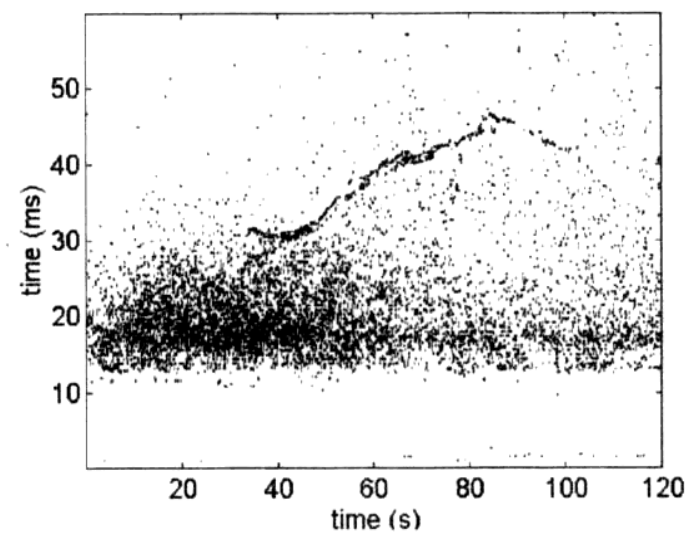

FIG. 3. Transecto $\mathrm{n}^{\circ} 14$ trace contour. W-E

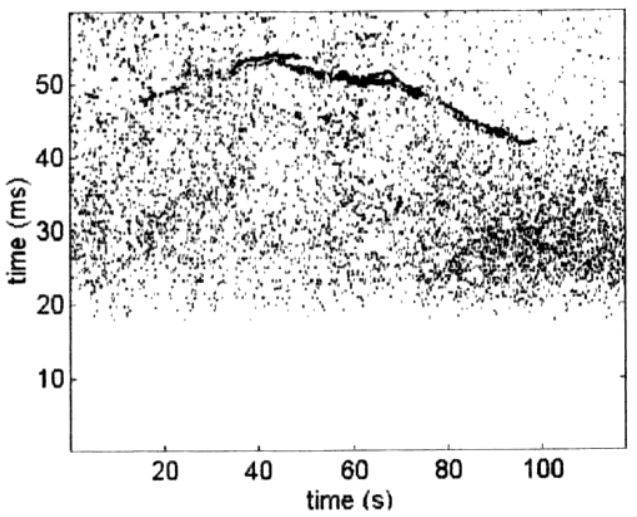

FIG.4. Transecto $\mathrm{n}^{\circ} 15$ trace contour (TVG). E-W

\section{ACKNOWLEDGMENTS}

The project was financially supported by the E.C.Common Fisheries Policy through the project "Study of alternatives for net location and/or identification: technical control device" 95/C $76 / 15$.

\section{REFERENCES}

1. Björnö I.K. \& Björnö L.,"Modeling of multiple scattering in suspensions," in Proc.of the $3^{\text {rd }}$ European Conf. on Underwater Acoustics, ed. J.S.Papadakis ( $\left.4^{\text {th }}-\mathrm{IACM}\right)$, Creta, pp. 87-92, 1996. 2. Hickling R., Journal of the Acoustical Society of America, 36, pp. 1124-1137 (1964).

3. Carbó R. \& Molero A.C., "Gillnet passive system echo-identification" in Proceedings of the $4^{\text {th }}$ Congress on Acoustics, edited by G. Canevet (Teknea), Marseille, pp. 1117-1120, 1997.

4. Clay C.S. \& Medwin H., Acoustical Oceanography (J.Wiley \& Sons), N.Y., 1977, pp.203-213.

5. MacLennan D. \& Simmonds E.,Fisheries Acoustics (Chapman \& Hall), London,pp.32-39, 1992. 